\title{
CHARACTERIZATION OF SOLDER FLOW ON PWB SURFACES
}

\author{
F. M. Hosking and F. G. Yost \\ Sandia National Laboratories \\ Albuquerque, NM
}

\begin{abstract}
Different solderability tests have been developed to determine the wetting behavior of solder on metallic surfaces. None offer an exact measure of capillary flow associated with conventional mixed technology soldering. With shrinking package designs, increasing reliability requirements, and the emergence of new soldering technologies, there is a growing need to better understand and predict the flow of solder on printed wiring board (PWB) surfaces. Sandia National Laboratories has developed a capillary flow solderability test, through a joint effort with the National Center for Manufacturing Sciences, that considers this fundamental wetting issue for surface mount technology. The test geometry consists of a metal strip (width, $\delta$ ) connected to a circular metal pad (radius, $r_{c}$ ). Test methodology, experimental results, and validation of a flow model are presented in this paper. ${ }^{*}$
\end{abstract}

\section{INTRODUCTION}

Most solder wettability tests ${ }^{1-4}$, such as the wetting balance, area-of-spread, meniscus rise, rotary dip, and globule tests, do not accurately represent solder flow or spreading during typical electronic assembly soldering operations. These "standard" tests poorly simulate the actual capillary flow physics of plated-through-hole (PTH) and surface mount technology (SMT) soldering. Such mixed technology processes usually involve solder flow along metallized surfaces into a small diameter annulus or the gap between a surface mount device and a printed wiring board. Production yield statistics and failure rate data, when available, have demonstrated the need for a solderability test that does a better job in predicting assembly level solderability. Just as critical is the need for a test that yields reproducible results.

The Center for Solder Science and Technology at Sandia National Laboratories has developed a capillary flow solderability test ${ }^{5-7}$ that incorporates the fundamental wetting behavior observed during surface mount soldering. The work is a joint venture between the federal government and several national electronics manufacturers to develop enabling technologies for the U.S. PWB industry. The work is being funded by the Departments of Commerce and Energy and managed by the National Center for Manufacturing Sciences. The test offers a potential soldering index for evaluating the effect of different surface finishes and geometries on solder flow. The technique can also be

\footnotetext{
* This work was performed at Sandia National Laboratories, which is supported by the U.S. Department of Energy under contract number DE-AC04-94AL85000.
}

used to control the delivery of solder to specific circuit locations.

Common to the test geometry is a metal strip extending from a circular pad (Fig. 1). Consider a circular metallization pattern having radius, $r_{\mathfrak{c}}$, and let a small volume of solder wet and spread to a radius $r$, such that $r<r_{c}$ and the capillary equilibrium occurs at a contact angle, $\theta_{0}$. Let the solder volume increase to a value $V_{0}$, just large enough for solder to spread to the metallization radius. Any further increase of volume will increase the contact angle to a value $\theta_{+}>\theta_{0}$, but will not increase the radius, since the wettable metallization extends only as far as $\mathbf{r}_{\mathbf{c}}$. In this constrained configuration, there exists an excess pressure that would drive solder flow, should more metallization be made available. Now consider additional metallization of a very slender rectangular strip of width $\delta<r_{c}$ connected to the circular pad as illustrated in Fig. 1. The excess pressure would move solder onto the strip for certain values of the ratio $\delta$ to $r_{\mathrm{c}}$. Solder would flow a distance, $\mathrm{z}$, reducing the pressure over the circular metallization until it equals that above the strip.

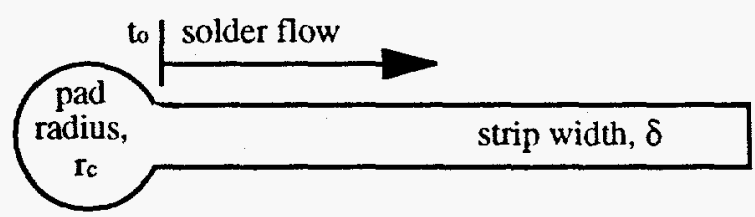

Figure 1. Solder capillary flow from the circular pad onto the connected metal strip depends on the ratio of line width to pad radius $\left(\delta / \mathrm{r}_{\mathrm{c}}\right)$.

To simplify modeling these flow conditions, it was assumed that the configuration geometry was small enough to neglect the effect of gravity on solder shape. Thus, the solder on the circular metallization is a spherical cap while the solder on the strip has a circular cross section. The height of solder on the strip is given by:

$$
h_{s}=\frac{\delta}{2}\left(\frac{1-\cos \theta_{s}}{\sin \theta_{s}}\right)
$$

where $\theta_{s}$ is taken to be the equilibrium contact angle on the strip. The mean curvature of the solder surface on the strip is: 


\section{DISCLAIMER}

Portions of this document may be illegible in electronic image products. Images are produced from the best available original document. 


$$
K_{s}=\frac{\sin \theta_{s}}{\delta}=1 / R_{\mathrm{s}}
$$

and the capillary pressure on the strip is:

$$
P_{s}=2 \gamma \frac{\sin \theta_{s}}{\delta}
$$

After solder flows onto the strip, a contact angle, $\theta_{c}$, is established on the circular metallization and the capillary pressure on the metallized pad is given by:

$$
P_{c}=2 \gamma \frac{\sin \theta_{c}}{r_{c}}
$$

In mechanical equilibrium, the capillary pressures, given by eqs. (3) and (4), must be equal, which yields the necessary geometric condition for wetting of:

$$
\frac{\delta}{r_{c}}=\frac{\sin \theta_{s}}{\sin \theta_{c}}
$$

If the strip length is sufficiently long for $\delta \neq \mathrm{r}_{\mathrm{c}}$, excess pressure will be zero and equilibrium must involve contact angle hysteresis, according to eq. (5), if the strip and circular metallizations are identical. Contact angle is known to be a function of the wetting velocity and even exhibits a range or band of static values, $2 \Delta \theta$, in mechanical equilibrium. These phenomena are collectively called contact angle hysteresis ${ }^{8}$ and are usually attributed to substrate surface roughness or chemical heterogeneity, common to most real surfaces, and can slow the smooth advance of the wetting front. With eutectic $\mathrm{Sn}-\mathrm{Pb}$ solder and a mildly activated rosin-based flux on wrought copper sheet, observed wetting or contact angles range from approximately $10^{\circ}$ to $20^{\circ}$. If $\theta_{o}$ is defined as Young's equilibrium contact angle, it should lie at the approximate center of the normal hysteresis range.

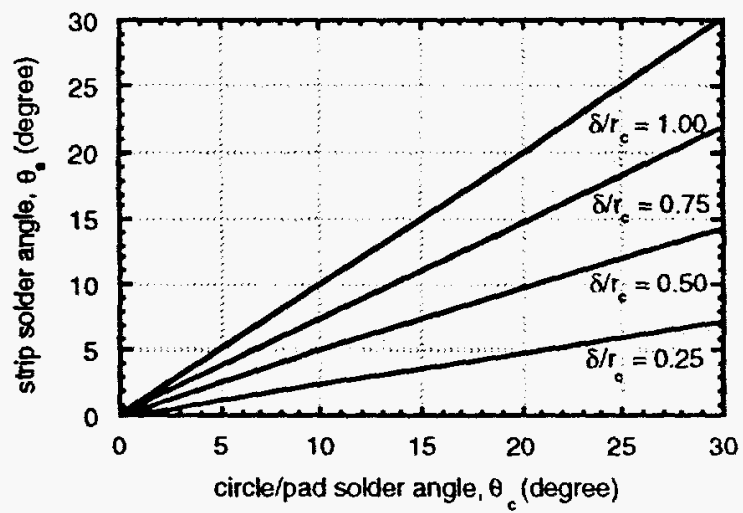

Figure 2. Equilibrium contact angle of solder on a circular metallization versus on a connected metallic strip for various strip width to circle radius ratios $\left(\delta / \mathbf{r}_{\mathrm{c}}\right)$.

For an equilibrium capillary configuration, $\theta_{s}$ and $\theta_{c}$ must be within or define the extremities of the range of stable contact angles, $2 \Delta \theta$. As solder flows onto the strip, it is reasonable to propose that the angle, $\theta_{+}$, on the circular pad decreases to a final contact angle, $\theta_{\mathfrak{c}}$, equal to $\theta_{o}+\Delta \theta$. For a given geometry, eq. (5) then specifies what value $\theta_{s}$ must take under equilibrium conditions. Figure 2 shows the relationship of $\theta_{s}$ and $\theta_{c}$ for various choices of $\delta / r_{c}$. For a Young's angle of $15^{\circ}$ and a hysteresis range of $2 \Delta \theta=10^{\circ}$, it is clear that for this range of contact angles, $\delta / r_{\mathfrak{c}}$ must be greater than approximately 0.5 if flow is to occur onto the strip. Only in this way will the two contact angles be contained within the stable hysteresis band. Note that if $\delta / r_{c}$ $=0.25$, there exists no combination of $\theta_{s}$ and $\theta_{c}$ lying within the $2 \Delta \theta$ hysteresis band that satisfies eq. (5). This implies that flow will not occur onto a strip having a very small $\delta / r_{c}$ ratio.

\section{MATERIALS AND TEST PROCEDURE}

The capillary flow test vehicle (CFTV) used in this study was fabricated using conventional PWB materials and fabrication technologies. The CFTV substrate was an epoxy resin laminate, $0.060^{\prime \prime}(1.52 \mathrm{~mm})$ thick, reinforced with glass fiber cloth (FR-4). Copper patterns $(0.5 \mathrm{oz}$.) were imaged and etched per the "lollipop" geometry described above. Additional copper was electrodeposited on the vendoretched $\mathrm{Cu}$ to a final thickness of $35 \mu \mathrm{m}(1 \mathrm{oz} . \mathrm{Cu})$.

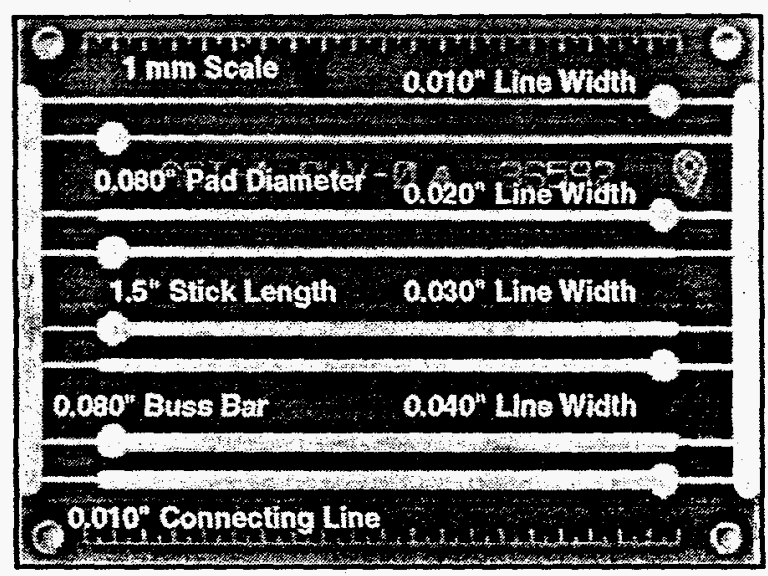

Figure 3. Capillary flow test vehicle (CFTV) with four different " $\delta$ to $r_{c}$ " patterns.

The layout of the test vehicle is shown in Figure 3. It has duplicate test pattems with line width-to-pad radius ratios $\left(\delta / r_{c}\right)$ of $0.25,0.5,0.75$, and 1.0 . The pad radius is a constant $0.040 "(1.02 \mathrm{~mm})$, with line widths of 0.010 , $0.020,0.030$, and $0.040^{\prime \prime}(0.25,0.51,0.76$, and $1.02 \mathrm{~mm})$. The line length, or maximum possible flow, is 1.5" (38.1 
$\mathrm{mm})$. One millimeter $(1.0 \mathrm{~mm})$ reference marks are also designed onto the test board as datums during subsequent video image wetting analyses. A buss bar and connecting conductive lines between test patterns are also available for depositing other surface finishes of interest (e.g., $\mathrm{Sn}-\mathrm{Pb}, \mathrm{Sn}$, $\mathrm{Ni}, \mathrm{Au}$, or $\mathrm{Pd}$ ).

Preliminary capillary flow experiments were conducted with eutectic $\mathrm{Sn}-\mathrm{Pb}(63 \mathrm{Sn}-37 \mathrm{~Pb}$, wt. \%) solder preforms. Test coupons were coated with a rosin mildly activated (RMA) solder flux, $25 \%$ solids. The capillary flow samples were cleaned before testing per the following procedure:

Test substrates were degreased in trichloroethylene, followed by an isopropyl alcohol rinse. They were then lightly etched in a 10 vol. $\% \mathrm{HCl}$ and deionized water solution for 3 minutes to remove a vendor-applied, benzotriazole-based organic solderability preservative, rinsed in hot tap water, rinsed in deionized water, rinsed in isopropyl alcohol, and finally blown dry with filtered technical grade nitrogen gas. Since most commercial precleaners are based on proprietary chemistries that are routinely modified, the generic cleaning procedure described above provides a more consistent method for preparing uniform baseline surfaces for testing.

Test boards were coated with flux after cleaning by gently agitating them in flux for 5 to 10 seconds. After slow withdrawal from the flux, the substrates were held vertically for approximately 15 seconds and blotted along their bottom edges to remove excess flux. Wetting tests were conducted with solder pellets of known weight and volume. Solder was placed on each circular metallized pad and then melted under simulated reflow conditions. In the event of no preheat, testing was performed after a 10-30 minute hold to permit volatilization of the alcohol or water carrier of the flux. This delay helped to improve solder flow by reducing flux splatter and evaporative cooling of the carrier ${ }^{5-6}$.

Capillary flow tests were conducted by either floating samples on a standard thermostatically controlled solder pot or transporting coupons through an inerted, conductively heated reflow machine. The solder pot was sufficiently large to float a test coupon without touching the sides of the pot. Samples were typically floated for $90-120$ seconds to achieve complete solder melting and flow. Pot temperatures were maintained within $\pm 2^{\circ} \mathrm{C}$. Simulated reflow soldering was conducted with a tabletop reflow system. The unit has four heat zones that were set at $40,120,226$, and $74^{\circ} \mathrm{C}$. The transport bar speed was 9 inches/minute for solder weighing less than $11 \mathrm{mg}$ and 5 inches/minute for anything above 11 $\mathrm{mg}$. Additional time was required to melt the larger solder preforms. The hot zone was fully inerted with technical grade nitrogen at a flow rate of $30 \mathrm{SCFH}$. After solder float and simulated reflow testing, flux residues were removed by cleaning in trichloroethylene.

Capillary flow data were analyzed from direct measurements and recorded video images. A black and white, chargedcouple device (CCD) camera and professional video tape recorder with time code generator were used to record the capillary flow test images. The camera was mounted such that its lens axis was perpendicular to the surface of floated test coupons. A fiber optic light source was used to illuminate the test surface. Solder flow images were recorded on video tape and stored on a hard disk attached to a personal computer (PC). Digital image analyses were subsequently conducted with a PC-based image processor and commercial image analysis software. Final wetted distance and flow rate on each strip were measured from the stored images. Data was taken from the point at which the molten solder began to flow down the test strip (time, $t_{0},=0$ ). The data were taken sequentially every second after $t_{0}$. The wetted distance was measured from the pad and strip intersection to the farthest distance where solder flowed.

\section{RESULTS AND DISCUSSION}

Experiments were conducted to determine the feasibility of the test method as a tool for assessing capillary flow on printed wiring boards. Test results were also used to validate the flow model. The capillary flow test conditions were as follows:

Solder Pellet Weight (mg) - 4.0, 10.3, 18.5

Solder Composition (wt. \%) - 63Sn-37Pb

Flux Type - Rosin Mildly Activated (RMA)

TV Surface Finish - Electroplated Copper

Solder Float Temperature Range - $230-260^{\circ} \mathrm{C}$

Peak Reflow Machine Temperature $-226^{\circ} \mathrm{C}$

Reflow Machine Atmosphere - Nitrogen, 30 SCFH

Initial testing was performed with the solder float heating procedure. The solder float tests clearly demonstrated the importance of preheating. Without a preheat, significant variability in wetting was observed and was dependent on the time elapsed after flux application (Fig. 4). This time dependency was lessened by introducing a preheat stage. Subsequent validation experiments, therefore, were conducted with a reflow profile that simulated typical assembly conditions.

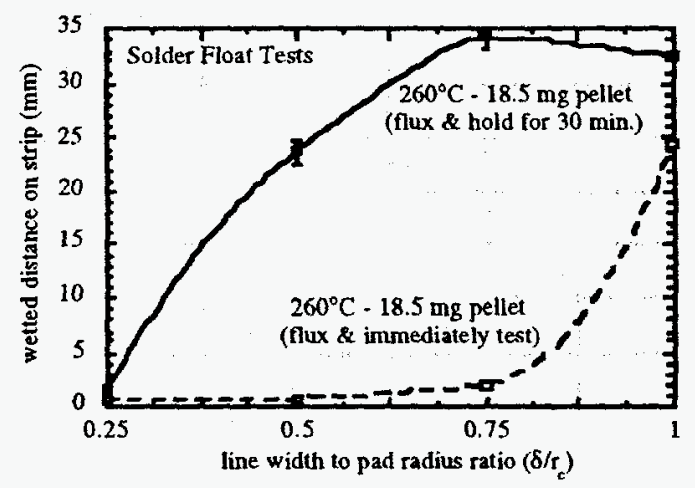

Figure 4. Time elapsed after applying flux significantly affects solder flow when preheating is not performed. Samples were solder floated immediately (bottom curve) or held for 30 minutes (top curve) after flux application.

The experimental wetting results agreed favorably with the flow model predictions. When $\delta / r_{c}$ was small, the only flow observed on the strip was a very small precursor foot. When 
$\delta / r_{c}$ was large enough to allow flow, solder was observed to flow slowly over the strip in a continuous manner, reaching equilibrium within 60 seconds.

Curves of distance wetted on the $0.030^{\prime \prime}(0.76 \mathrm{~mm})$ strip as a function of time from two identical $245^{\circ} \mathrm{C}, 10.3 \mathrm{mg}$ float tests are shown in Fig. 5. The time axis was shifted by a value $t_{0}$ to allow flow to commence at the origin. The initial rate of wetting was approximately $0.017 \mathrm{~cm} / \mathrm{s}$.

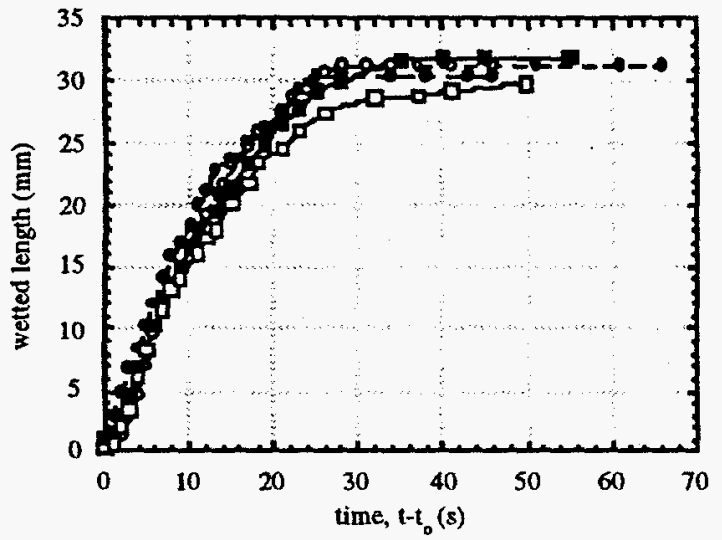

Figure 5. Kinetic data from two capillary flow tests on 0.76 $\mathrm{mm}$ wide strips with $10.3 \mathrm{mg}$ of solder at $245^{\circ} \mathrm{C}$.

The flow model suggests that, for a Young's angle of $15^{\circ}$ and a hysteresis range $2 \Delta \theta=10^{\circ}$, as in typical solders, $\delta / r_{c}$ must exceed 0.5 for flow to occur. Surface simulations ${ }^{7}$ for a system with $\theta_{0}=15^{\circ}$ agree well with these predictions. When $\delta / \tau_{\mathrm{c}}$ is less than 0.5 , the liquid remains on the circular pad except for a short precursor foot of liquid which extends onto the strip and increases in length as $\delta / r_{c}$ increases. When $\delta / \mathrm{r}_{\mathrm{c}}$ exceeds 0.5 , liquid flows down the strip, as experimentally confirmed.

There is another type of contact angle flexibility in solder/metallization systems which could influence capillary flow. A surface tension balance at the edge of the metallization pad could be maintained when the contact angle, relative to the test plane, is $\theta_{o} \leq \theta<\theta_{o}+90^{\circ}$. Modeling results ${ }^{7}$ show that the droplet contact angle on the circular metallization pad is much greater than $\theta_{o}+\Delta \theta$ $\left(-20^{\circ}\right)$, even in a non-flowing bubble. In addition, the corner where the circular pad meets the strip is the area of greatest contact angle $\left(-105^{\circ}\right)$. Therefore, it appears that the impediment to flow occurs at the entrance corner from the pad to the strip, and the contact angle flexibility that is important to flow is the flexibility at the edge of the metallization pad. The quantitative agreement between the surface simulations and the flow analysis, based on contact angle hysteresis, may be a coincidence and requires further examination.
The final part of this investigation involved validating the flow model by comparing the experimental and computed (eq. 5) solder contact angles on the different strips. Both values were dependent on the developed $\delta / r_{c}$ and contact angle relationship. The validation experiments were performed in the inerted reflow machine with the three solder preform weights listed above. Maximum wetted lengths and solder-pad contact angles were directly measured from the tested coupons. A goniometer was used to make the angle measurements. The instrument images the solder-pad free surface through an eyepiece. After setting a baseline reference while viewing the sample, the contact angle is determined by rotating the measuring dial on the eyepiece to correspond to the angle made between the reference line and the tangent at the solder-pad contact point. Since the pad geometry is symmetrical, the measurement was not dependent on pad orientation.

Strip angles were determined by cross-sectioning through the solder wetted strips. The solder-strip free surfaces were photographed at 100 times magnification for the 30 and 40 mil wide strips and 200 times magnification for the $20 \mathrm{mil}$ wide strips. Contact angles were then directly measured from the photographed images. The results from the validation experiments are summarized in Table 1 . As predicted by the flow model, poor wetting occurred on the 10 mil strips with negligible flow onto the strip.

Table 1.

Measured Wetted Distance \& Contact Angle Data

$\begin{array}{lllll}\begin{array}{l}\text { Line } \\ \text { Width } \\ \text { (mils) }\end{array} & \begin{array}{l}\text { Solder } \\ \text { Weight } \\ (\mathrm{mg})\end{array} & \begin{array}{l}\text { Wetted } \\ \text { Length } \\ (\mathrm{mm})\end{array} & \begin{array}{l}\text { Pad } \\ \text { Angle } \\ \text { (degree) }\end{array} & \begin{array}{l}\text { Strip } \\ \text { Angle } \\ \text { (degree) }\end{array} \\ 10 & 4.0 & \text { none } & 29.6 \pm 2.0 & \text { none } \\ 10 & 10.3 & \text { none } & 64.9 \pm 4.9 & \text { none } \\ 10 & 18.5 & \text { none } & 88.4 \pm 1.6 & \text { none } \\ 20 & 4.0 & 1.3 \pm 1.1 & 27.0 \pm 2.5 & \text { none } \\ 20 & 10.3 & 16.0 \pm 7.9 & 53.9 \pm 5.5 & 19.0 \pm 0.8 \\ 20 & 18.5 & 28.9 \pm 11.8 & 77.2 \pm 9.1 & 24.3 \pm 1.0 \\ 30 & 4.0 & 7.1 \pm 1.9 & 16.8 \pm 2.9 & 12.8 \pm 0.6 \\ 30 & 10.3 & 24.9 \pm 2.6 & 23.3 \pm 3.5 & 16.9 \pm 1.1 \\ 30 & 18.5 & 34.0 \pm 4.3 & 32.1 \pm 3.6 & 23.1 \pm 2.7 \\ 40 & 4.0 & 6.7 \pm 1.7 & 105 \pm 2.3 & 10.9 \pm 0.6 \\ 40 & 10.3 & 20.5 \pm 2.1 & 12.4 \pm 2.0 & 13.3 \pm 2.2 \\ 40 & 18.5 & 31.2 \pm 6.7 & 17.2 \pm 6.2 & 16.6 \pm 1.1\end{array}$

Experimental and modeling results are graphically presented in Figs. 6-9. Fig. 6 summarizes the distance that solder flowed onto the different strip widths. Best flow was observed on the $30 \mathrm{mil}$ strip. The wetted distance was generally less on the $40 \mathrm{mil}$ strip. The lower values were attributed to the larger surface area that solder had to flow over on the wider strip. The effect of the $\delta / r_{c}$ geometry on restricted flow was clearly demonstrated by the 10 and 20 mil strips, where flow was generally negligible or less than the 30 and $40 \mathrm{mil}$ results. The initiation of solder flow on a 20 mil strip with a $4 \mathrm{mg}$ solder preform is shown in Fig. 7. Note the precursor at the tip of the advancing solder front. 


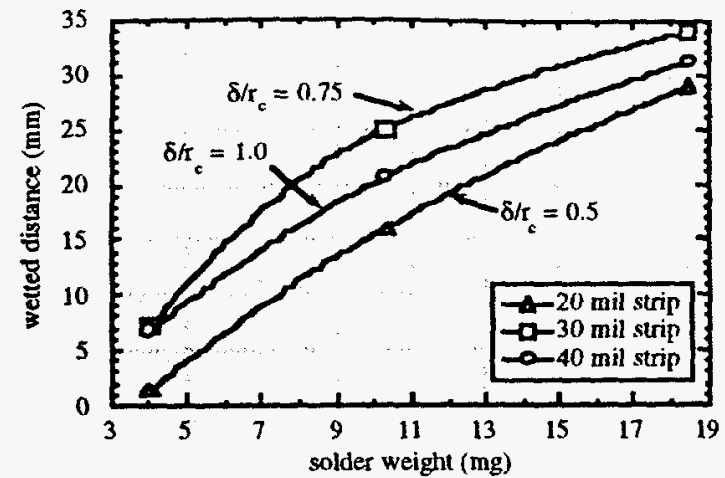

Figure 6. Wetted distance of solder on the attached strips as a function of the initial solder weight and $\delta / r_{c}$ value.

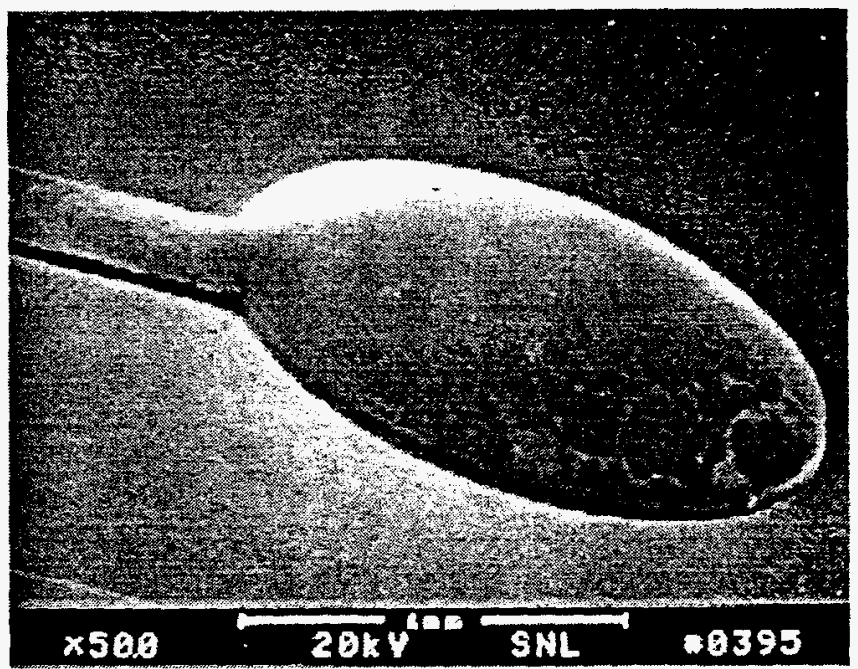

Figure 7. Scanning electron microscope photomicrograph of solder (4 mg) initiating flow onto a 20 mil wide copper strip from an 80 mil diameter pad.

The experimental results for the measured solder-pad contact angles, $\theta_{c}$, are summarized in Fig. 8. As solder flowed out onto the attached strips, the angle on the pad decreased. The 10 and 20 mil strips not only exhibited the poorest wetting results, but they also yielded the largest range of pad contact angles for the tested solder weights. This $50-60^{\circ}$ range represents the hysteresis growth of solder on the pad and is driven by the inability of the solder to flow onto the narrow strips. The same phenomenon was not observed on the wider 30 and $\mathbf{4 0}$ mil strips, since the restriction to solder flow was diminished. The rate at which the angle changes is dependent on both the strip width and solder weight (i.e., solder volume). Under equilibrium conditions, a wider strip lowers the canillary pressure over the strip (eq. 3) and results in a lower pad pressure. Since the pad radius is fixed, the solder contact angle on the pad must also decrease (eq. 4). By increasing the solder volume and restriction to flow, the range of angles, $\Delta \theta_{c}$, is increased. This expanding range represents the hysteresis band depicted in the fundamental capillary flow models described above. As one would expect, it plays a critical role in test repeatability.

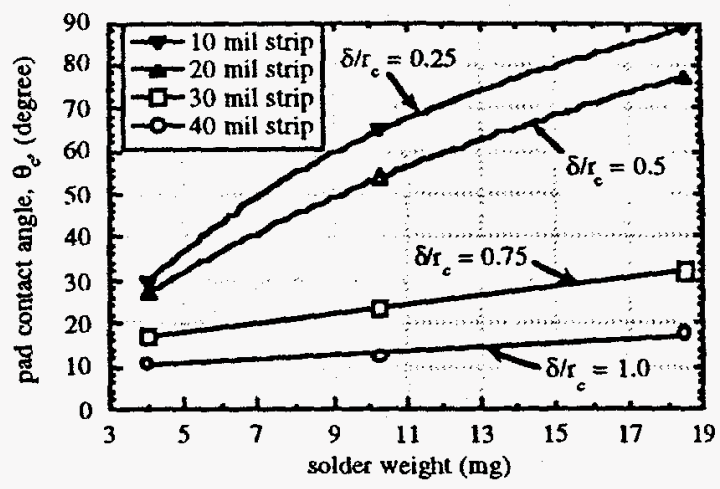

Figure 8. Measured solder-pad contact angle, $\theta_{c}$, on the different test pads as a function of the initial solder weight.

The results for the measured solder-strip contact angles, $\boldsymbol{\theta}_{\mathbf{s}}$, are summarized in Fig. 9. No flow was observed on the fine, 10 mil strip, as predicted by the flow model. Flow was observed on the 20 mil strips, but only after the solder weight exceeded $4 \mathrm{mg}$. The strip angles, $\theta_{\mathrm{s}}$, were also computed by substituting the measured pad angles and $\delta / r_{\mathfrak{c}}$ values into eq. 5 . The measured solder contact angles on the strip compared very well with the computed values (Table 2). The $10 \mathrm{mil}$ strips had the greatest variability. Considering the potential effect of hysteresis on flow, the results were well within experimental error. Agreement was especially good for the 30 and 40 mil lines.

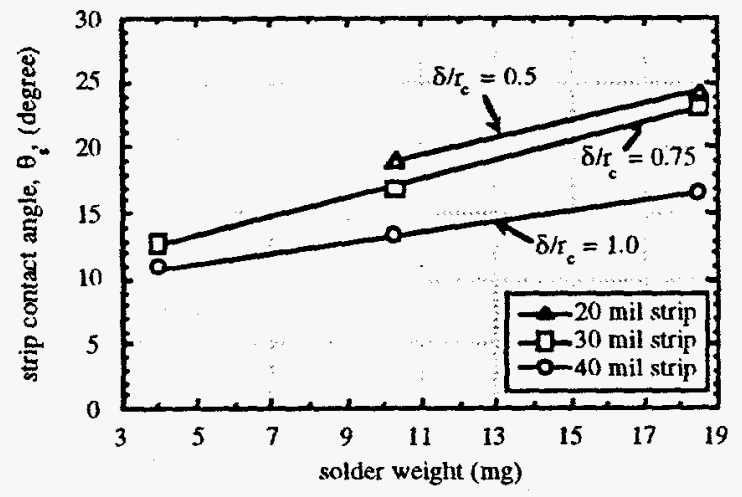

Figure 9. Measured solder-strip contact angle, $\theta_{\mathrm{s}}$, on the different test strips as a function of the initial solder weight.

In summary, this investigation has developed and validated a capillary flow model that represents solder flow from a metallized pad onto an attached strip. The test geometry is common to most surface mount circuits. The model presents a fundamental understanding of capillary flow on a PWB. As advanced circuit designs become increasingly smaller and complex, the ability to accurately predict enhanced or 
restricted solder flow by modifying surface geometry will lead to more producible and reliable solder joints and enable the next generation of PWB interconnection technologies.

Table 2.

Comparison of Measured and Computed Strip Angles

$\begin{array}{llll}\begin{array}{l}\text { Line } \\ \text { Width } \\ \text { (mils) }\end{array} & \begin{array}{l}\text { Solder } \\ \text { Weight } \\ \text { (mg) }\end{array} & \begin{array}{l}\text { Measured } \\ \text { Strip Angle } \\ \text { (degree) }\end{array} & \begin{array}{l}\text { Computed } \\ \text { Strip Angle } \\ \text { (degree) }\end{array} \\ 10 & 4.0 & \text { none } & 7.1 \\ 10 & 10.3 & \text { none } & 13.1 \\ 10 & 18.5 & \text { none } & 14.5 \\ 20 & 4.0 & \text { none } & 13.1 \\ 20 & 10.3 & 19.0 \pm 0.8 & 23.8 \\ 20 & 18.5 & 24.3 \pm 1.0 & 29.2 \\ 30 & 4.0 & 12.8 \pm 0.6 & 12.5 \\ 30 & 10.3 & 16.9 \pm 1.1 & 17.3 \\ 30 & 18.5 & 23.1 \pm 2.7 & 23.5 \\ 40 & 4.0 & 10.9 \pm 0.6 & 10.5 \\ 40 & 10.3 & 13.3 \pm 2.2 & 12.4 \\ 40 & 18.5 & 16.6 \pm 1.1 & 17.2\end{array}$

\section{CONCLUSIONS}

A capillary flow model was developed to predict solder flow onto a metallized strip. Conditions for the initiation of flow were determined. Flow was dependent on the geometric relationship between the strip width, $\delta$, and the attached pad radius, $r_{c} . A \delta / r_{c}$ value of at least 0.5 was necessary for flow to occur. The relationship between the solder contact angle on the strip, $\theta_{\mathrm{s}}$, and pad, $\theta_{\mathrm{c}}$, was verified by comparing the measured and computed angles. Greater variability in the flow data was observed on the small strips, where the opportunity for hysteresis was greatest.

\section{ACKNOWLEDGMENTS}

The authors would like to acknowledge the support of the National Center for Manufacturing Sciences, particularly the
Surface Finishes Team from the PWB Interconnect Systems program. The authors would also like to acknowledge the contributions of the following Sandians: Cindy Hernandez, Susan Sackinger, Darrel Frear, Danny MacCallum, Elizabeth Holm, Richard Chavez, Fred Greulich, and Bonnie McKenzie. The manuscript was reviewed by Eddie Lopez.

\section{REFERENCES}

(1) Wassink, R. J. Klein, Soldering in Electronics, Electrochemical Publications Limited, Second Edition, 1989, Pages 36-83 and 300-370.

(2) Lea, C., A Scientific Guide to Surface Mount Technology, Electrochemical Publications Limited, 1988, Pages 308-377.

(3) Solderability Tests for Printed Boards, ANSI-J-STD003. The Institute for Interconnecting and Packaging Electronic Circuits (IPC) and Electronic Industries Association (EIA), 1992.

(4) Yost, F. G., Hosking, F. M., and Frear, D. R. (Eds.), The Mechanics of Solder Alloy Wetting and Spreading, Van Nostrand Reinhold, 1993, Pages 9-33.

(5) Hosking, F. M., Yost, F. G., Hernandez, C. L., and Sackinger, S. J., "Capillary Flow Solderability Test for Printed Wiring Boards", Sandia Report SAND94-0603, April, 1994.

(6) Hosking, F. M., Yost, F. G., Hernandez, C. L., and Sackinger, S. J., "Assessing Capillary on Printed Wiring Board Surfaces", Advances in Electronic Packaging 1995, INTERpack '95 Proceedings, March 1995, ASME EEP-Vol. 10-1, Pages 1107-1111.

(7) Yost, F. G., and Holm, E. A., "Capillary Flow on Narrow Strips and V-Shaped Grooves", Advances in Electronic Packaging 1995, INTERpack '95 Proceedings, March 1995, ASME EEP-Vol. 10-1, Pages 1265-1271.

(8) Marmur, A., "Thermodynamic Aspects of Contact Angle Hysteresis", Advances in Colloid and Interface Science, 1994, Vol. 50, Pages 121-141.

\title{
DISCLAIMER
}

\begin{abstract}
This report was prepared as an account of work sponsored by an agency of the United States Government. Neither the United States Government nor any agency thereof, nor any of their employees, makes any warranty, express or implied, or assumes any legal liability or responsibility for the accuracy, completeness, or usefulness of any information, apparatus, product, or process disclosed, or represents that its use would not infringe privately owned rights. Reference herein to any specific commercial product, process, or service by trade name, trademark, manufacturer, or otherwise does not necessarily constitute or imply its endorsement, recommendation, or favoring by the United States Government or any agency thereof. The views and opinions of authors expressed herein do not necessarily state or reflect those of the United States Government or any agency thereof.
\end{abstract}


Unofficial

Officlal

MANUSCRIPT RECORD OF REVIEW

Unlimited

ORGANIZATION 1800

Limited

Journal

TITLE: CHARAETERIZATION OF SOLDER FLOW

$$
\text { ON PWB SURFACES }
$$

AUTHOR: F.M. HOSKING 4 F. G. YOST

DOCUNENT NO.:

JOURNAL/MEETING: SURFAEE MOUNT INTERNATIONAL

CONF. PROCEEDINGS (AUG. 95)

DRAFT FOR REVIEW: FTOM: F.M. HOSKING

$$
\begin{aligned}
& \text { To: E, LOP } \\
& \text { To: } \\
& \text { Return to Author: }
\end{aligned}
$$

GUIDE FOR TECHNICAI REVIEWERS

The reviewer will look critically at the technical aspects of the report with respect to the following:

(1) Organization and clarity of presentation.

(2) Correctness of assumptions.

(3) Validity of data (Including statistical significance).

(4) Adequacy of discussion of varlables.

(5) Validity of conclusions and recommendations.

(6) Adequacy of 1llustrations, graphs, tabular data, etc.

He will also comment concerning:

(1) Appropriate acknowledgment of contributors.

(2) Conciseness.

(3) Inappropriate statements.

(4) Any other constructive criticism.

The reviewer 111 make h1s comments on separate sheets of paper, inftial the comment sheets, attach the comment sheets to the draft, and return the draft with coments to the author. Comments should refer to page, paragraph, and sentence. Revlewers must be critical if they are to make contributions to better quality reports.

NOTE: The technical reviewer must be someone other than the writer's Division Supervisor. The two technical reviewers may be anyone in the Corporation mutually agreed upon by the author and his Division Supervisor. 